\title{
Systemic experiential learning model for the evaluation of technological learning: the case of small satellite capability-building in Algeria.
}

\author{
Ahmed Ayad, Cranfield University, UK \\ Edith Wilkinson, Cranfield University, UK \\ Ron Matthews, Cranfield University, UK
}

\begin{abstract}
This article proposes a 'systemic experiential learning model' for the evaluation of technological learning. Technological learning is effective when combining learning by doing, by searching and by interacting. The proposed model is based on parallels drawn between the typology -learning by doing, by searching and by interacting- and the Kolb's Experiential Learning Theory through its cyclical combination of action and reflection. It argues that learners, whether they be individuals, groups, organisations, or inter-organisations, are more effective when completing Kolb-like cycles. The proposed model is the combination of horizontal and vertical processes. Each learning level (individual, group, organisation or inter-organisation) is modelled, horizontally, according to a Kolblike learning cycle. Vertical connections are made between the horizontal levels of aggregation by borrowing March's concepts of 'exploration' and 'exploitation'. The model has been used for the evaluation of learning occurring in the Algerian small satellite capability-building programme. The implementation of the model revealed that learning is not systemic and therefore ineffective. Findings are reflective of the difficulty of striking the right balance between action (learning by doing) and reflection (learning by searching) and densifying interactions (learning by interacting) within and between learning levels.
\end{abstract}

Keywords: Technological learning; experiential learning; knowledge diffusion; technological capability-building; small satellite.

\section{1- Introduction}

Knowledge is viewed as a resource at the core of organisation development (Alvarez and Busenitz, 2001). The present paper lies within this knowledge-based tradition and looks at technological capability-building from a learning perspective. Technological capability-building refers to the learner's ability to acquire, appropriate (i.e. modify, improve, innovate) and diffuse knowledge (Kim, 1997). Learning is viewed as a systemic phenomenon involving multiple learning levels (individual, group, organisation and inter-organisation) that interrelate with each other (Dixon and Flood, 1993; Russ-Eft et al., 1997; Gill, 2010; Hargadon, 2013; Holmqvist, 2003). Based on this approach, the article proposes a 'systemic experiential learning model' for the evaluation of technological learning in developing countries. In a technological context, learning is effective when combining learning by doing, by searching and by interacting (Garud, 1997; Kim, 1993). The proposed 'systemic experiential learning model' combines these learning types at various learning levels by using Kolb's (1984) Experiential Learning Theory (ELT) and March's (1991) concepts of 'exploration' and 'exploitation'. The proposed model is built by drawing parallels between the typology of technological learning -by doing, by searching and by interacting- and Kolb's combination of action and reflection.

The particular selection of Kolb's theory lies in the fact that his theory is extremely influential (Beard and Wilson, 2006) and his descriptive model has proven to be a powerful assessing tool in learning 
programmes (Tennant, 2006). The original analytical focal level of Kolb's ELT was the individual. This article examines its extensions to other levels of analysis (i.e. group, organisation and interorganisations). It is argued that intra-level learning is effective when learners, whether they be individuals, groups, organisations, or inter-organisations, complete Kolb-like cycles. As regards the interrelations between learning levels, the proposed model borrows from March (1991)'s concepts of 'exploration' and 'exploitation' to link the learning levels to each other. The resulting 'systemic experiential learning model' represents the systemic phenomenon of learning by combining intraand inter-level interactions. The model has been tested on the Algerian programme of small satellite capability-building. The implementation of the model aims to evaluate the level of local diffusion of small satellite technology acquired from abroad. It evaluates knowledge diffusion or learning occurring within the Algerian space agency and its environment.

The article examines the interconnection between learning levels (section 2) and discusses individual-focused Kolb's ELT and its extensions to group, organisation and inter-organisations levels (section 3). It subsequently examines the prominent technological learning typology: learning by doing, by searching and by interacting (section 4). The proposed 'systemic experiential learning model' is then formulated (section 5) and applied to small satellite capability-building in Algeria (section 6). Finally, findings are discussed and a conclusion is offered (section 7).

\section{2- The intertwining of learning levels}

The literature on learning conventionally identifies several learning levels: individual, group, organisation and inter-organisation (Dixon and Flood, 1993). The individual level is foundational, in the sense that effects at that level can be enriched and converted through interactions into group opportunities and then embedded and amplified into the context of an organisation or interorganisation. Gill (2010) argues that individual learning depends both on individuals and the organisation. The former have the responsibility to seek their own development; the latter has the responsibility to offer an environment conducive to learning. By learning, individuals should attempt to build capacity to achieve the organisation's goals and not simply seek their own personal interest. Group learning, by contrast, occurs when knowledge is held by the group as a whole and not by any single individual (Gill, p.35). It results from individuals who share group values and contribute to achieving the group's goals. According to Russ-Eft et al. (1997), knowledge resulting from group learning is a continuous accumulative process of knowledge about the organisation, the group and the individuals. The third learning level is organisational learning, which does not stem from mere aggregation of individual learning, but hinges on further factors, such as individual learning processes gathered within the organisation as a learning system, and the organisation memory (Dasgupta, 2012).

Finally, there is inter-organisational learning, which results from the influence of one organisation on the capacities of another through interactions (Ingram, 2002). Interactions enable experience sharing and stimulate innovation (Ingram, 2002). Hargadon (2013) stresses that interactions within specific domains or fields produce shared understandings and appropriate actions. Whilst such dynamics create constraining effects, they also generate favourable conditions for innovation. Holmqvist (2003) explains the deeply interlaced processes of learning within an organisation (i.e. intra-organisation) and between organisations (i.e. inter-organisation). He argues that intraorganisational learning is to some extent an inter-organisational 'affair' as interactions between an organisation and its environment cannot be overlooked. 
In summary, then, there is a need to recognise that learning is a complex phenomenon insofar as processes occurring at separate levels are in fact interrelated. Several authors suggest that successful learning leads to a systemic phenomenon where the interplay involves all levels of aggregation, from individuals to inter-organisations (Rousseau, 1985; Coghlan, 1997; Beeby and Booth, 2000).

\section{3- Experiential learning at individual, group, organisation and inter-organisation levels}

Kolb's (1984) ELT, particularly its cyclical model, has had a dramatic impact on learning literature at the individual level, which was Kolb's original focal level of analysis. This section examines Kolb's ELT and its extensions to other levels of analysis (group, organisation and inter-organisation).

\section{3-a- Kolb's ELT: a framework for individual learning}

Kolb (1984) defines learning as "the process whereby knowledge is created through the transformation of experience" (p.38). He claims that "knowledge results from the combination of grasping experience and transforming it" (p.41). He dissected this vision into a model of a four-stage learning cycle (Figure 1) and argues that learning is effective when it is holistic and combines experience, perception, cognition and behaviour (referred to as concrete experience, reflective observation, abstract conceptualisation and active experimentation).

Figure 1: Experiential Learning Cycle and basic learning styles

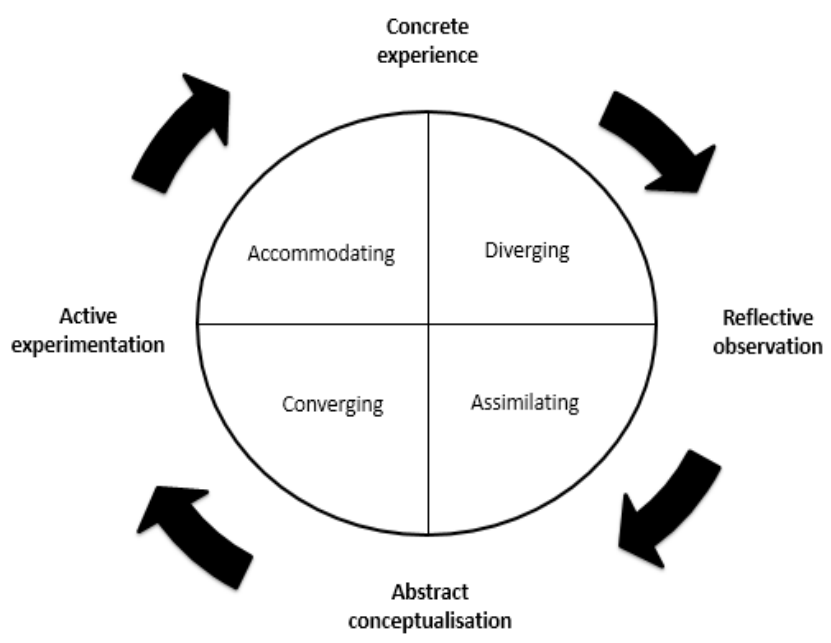

Source: adapted from (Kolb, 1984).

Kolb (1984) emphasises that learning is effective when it is holistic. Fundamentally, this happens when both dimensions, reflection and action, are combined during the learning process. However, Kolb recognises the conflict between these two dimensions of learning whereby the learner "moves in varying degrees from actor to observer and from specific involvement to general analytic detachment" (p.31). These opposing tensions are constantly at play and require individuals to combine reflective abilities (theoretical) and action (concrete and practical). Kolb states that combining conflicting abilities is not always a natural task, arguing that individuals thrive from their own experience, based on their own set of learning abilities. In other words, individuals develop their particular learning styles throughout their lives. Four learning styles are therefore identified (Figure 1): diverging, assimilating, converging and accommodating (Kolb and Kolb, 2005). Each individual tends to enter the learning cycle from the point that corresponds to the strongest abilities (or preferred style), and the whole cycle then needs to be completed for learning to be effective. 


\section{3-b- Kolb's ELT expanded to group learning}

The prevailing efforts in the workplace are work carried out by groups or teams of individuals; there is consequently a need to continuously develop individuals' skills for teamwork (Stevens and Campion, 1994) and a requirement to overcome barriers to team building by promoting organisational and management capabilities to work in increasingly demanding contexts (Mills, 1967). This dynamic involves successive and increasingly sophisticated levels of abilities for a team facing increasingly sophisticated purposes (Mills, 1967). Such increasingly complex purposes have been categorised by Kayes et al. (2005) as team developmental stages, with the authors arguing that Kolb's ELT can be used as a framework that shows a team moving from lower to higher stages. This brings to light two fundamental aspects of team experiential learning. Firstly, the incidence of a conversation space for the team where members talk about their experience, reflect on actions and consequences and share the desire to grow together. Secondly, the ability of team members to evolve from individual roles to shared responsibilities and team roles. For these conditions to be met, Kayes et al. (2005) argue that teams should enter the experiential learning cycle and "must have members who can be involved and committed to the team and its purpose (concrete experience), who can engage in reflection and conversation about the team's experiences (reflective observation), who can engage in critical thinking about the team's work (abstract conceptualisation), and who can make decisions and take action (active experimentation)" (p.335). Put simply, the teams must be composed of members with diverse learning styles.

\section{3-c- Organisational learning cycle and Kolb's ELT}

An early indication of the organisation relevance of the Kolb ELT was provided by Swieringa and Wierdsma (1992). The authors argue that organisations learn effectively when they combine reflection and action, and "while [Kolb's cycle] is true for individual learning, it is even more so for a collective learning process, a process of organizational learning" (p.89). This connection between organisational learning and Kolb's experiential learning cycle reflect that the phases of learning which take place at individual level bear relation to the collective context (Dixon, 1999, p.65). She offers a four-phase model inspired by Kolb's learning cycle that fits into the organisational context (Figure 2).

Figure 2: Organisational learning cycle and Kolb's experiential learning cycle

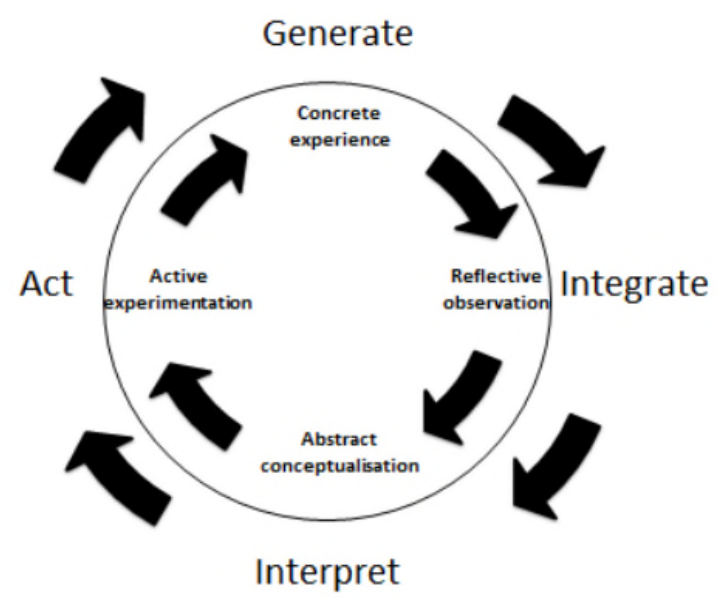

Source: adapted from (Dixon, 1999, p.65).

The initial step of the cycle deals with 'concrete experience'. In this phase and in order to better deal with complexity, organisations need to diversify and broaden their sources of information 
(generating information). Subsequently comes a phase of integration of information corresponding to Kolb's 'reflective observation'. The next step is the collective interpretation of information that relates to 'abstract conceptualisation' in the Kolb model. The final step is action and corresponds to 'active experimentation'. The actions taken will serve as sources of new information.

\section{3-d- Inter-organisational learning cycle and Kolb's ELT}

Inter-organisational learning experience is built over time through dense and continuous interactions between organisations (Hargadon, 2013). Beeby and Booth (2000) reject the assumption that inter-organisational relations are inherently competitive. Instead, they put forward the need for complementarity and integration between organisations, similar to that needed between departments of the same organisation. The authors draw connections between Kolb's cycle and inter-organisational learning by building on Coghlan's (1997) inter-departmental framework, where learning at inter-departmental level is modelled according to a Kolb-like cycle (ExperiencingProcessing-Interpreting-Taking action).

The rational in this section is that learners, whether they be individuals, groups, organisations or inter-organisations, might be more effective when achieving a tension-filled process combining action (practical aspects) and reflection (theoretical aspects). This is challenging in the context of developing countries as many of them have had limited exposure to learning combining action and reflection (Saad, 2004; Saad and Zawdie, 2005). The development strategies of numerous developing countries rely on knowledge acquired from abroad combined with knowledge generated endogenously. Studies revealed that the strategy of acquiring knowledge from abroad often overemphasises the action and practical aspects of learning (e.g. through industrial programmes, consulting) and overlooked the theoretical basis underlying the transferred knowledge (Saad, 2004; Saad and Zawdie, 2005). On the other hand, when the strategy is based on endogenous development, the role of local education is crucial (Varsakelis, 2006). However, because of limited local financial and managerial resources, indigenous education (or human skills development) systems in many developing countries marginalise practical work and experimentation and limit education to some theoretical aspects (Bederina, 2011; Chitour, 2016). In both strategies, the learning cycle is interrupted and many developing countries have not enough exposure to effective learning processes where action and reflection were successfully combined. These countries lack established practices in holistic learning.

\section{4- The triad: learning by doing, by searching and by interacting}

The triad learning by doing, learning by searching and learning by interacting is one of the most revered typologies in technological learning. Learning results from experience, also referred to as learning by doing, by which knowledge is accumulated gradually via repeated production activities and attempting to solve problems at hand (Garud, 1997). At organisational level, Argote and Epple (1990) explain that depreciation in learning by doing may be caused by factors such as organisational forgetting. UNIDO (2005) stresses the importance of routine management in the process of learning by doing. Teece (2000) explains that learning by doing is not automatic as it requires consideration and explicit efforts.

Garud (1997) argues that learning by doing creates only one component of technological knowledge, representing an "understanding of the generative processes that constitute phenomena" (p.81). He 
considers that intellectual capital involved in technological learning encompasses other components. Bell (1984) recognises that besides learning by doing that aims to increase production using the same technological capability, another learning type called learning by searching exists. It is an active learning process aimed at improving the existing technological capability (continuous change) or moving to new kind of technological capability (discontinuous change) (Dosi, 1982). Garud and Rappa (1994) point out the paradoxical demand on learners at individual and organisational levels. On the one hand, they are asked to stick to the same technological trajectory by developing beliefs about technical feasibility, an understanding about the artefacts they create and compliance towards routines used to evaluate their effort. On the other hand, they are asked to challenge these beliefs and realities in order to change and innovate. Learning by searching creates another component of technological knowledge, which aims at an "understanding of the principles underlying phenomena" (Garud, 1997, p.81).

Searching involves experimentation and simulation to understand phenomena. Malerba (1992) explains that R\&D activities are a significant enabler of learning by searching whether they are conducted endogenously through formal R\&D, or exogenously by carrying out a technology watch (e.g. scientific and technological publications, seminars, patent analysis).

Malerba (1992) considers that interaction enables knowledge acquisition from external sources (i.e. learning by interacting). Upstream and downstream (e.g. suppliers and customers) interactions are referred to as vertical or value chain interactions. Horizontal interactions refer to cooperation with horizontal organisations, such as firms in the same industry that may belong to the same supply chain, as well as research organisations. Horizontal interactions are more likely to produce a discontinuous change (technological innovation) than vertical interaction (Piek, 1998). The latter leads to more continuous change along the same technological trajectory (i.e. incremental innovation). However, in today's ever-changing environment, knowledge created through vertical interaction does not necessarily accumulate and is not necessarily path-dependent (Garud, 1997). Kenney (2001) provides the example of highly knowledge-intensive industries, such as electronics and computer networking, where the pace of new knowledge creation may destroy the recently created knowledge value.

In a technological context, when learning by doing, by searching and by interacting are combined together, the learner's ability to effectively take action increases significantly. Kim (1993) illustrates this ability through the example of a carpenter's limited effectiveness if he masters woodworking skills (i.e. knowledge created by learning by doing) without mastering the knowledge of house structures and architecture (i.e. knowledge created by learning by searching) and vice-versa. In the same vein, a carpenter's abilities will be limited if he does not sufficiently interact (learning by interacting) with his environment (e.g. suppliers, customers, other carpenters) to become exposed, for instance, to techniques used elsewhere.

\section{5-The proposed model}

Learning is a systemic phenomenon that can be dissected according to vertical and horizontal differentiation (Rousseau, 1985). Each learning level (individual, group, organisation or interorganisation) can be modelled, horizontally, according to a Kolb-like learning cycle (see section 3). In this sense, horizontal refers to intra-level learning. Vertical connections are made between the horizontal levels of aggregation by borrowing March's concepts of 'exploration' and 'exploitation' (March, 1991). Vertical connections refers to the cross-level learning. The resulting systemic experiential learning model is, thus, the combination of vertical and horizontal processes. 


\section{5-a- Intra-level learning (horizontal differentiation)}

As discussed in section 3, learners, be they individuals, groups, organisations, or inter-organisations, are more effective when completing Kolb-like cycles. These cycles are tension-filled processes where action (i.e. practical aspects) is combined with reflection (i.e. theoretical aspects). As discussed in section 4, the literature on technological learning identifies three types of learning: learning by doing; learning by searching; and learning by interacting. From a technological perspective, learning is effective when it combines these three types of learning; however, this combination has not attracted sufficient attention in the literature. Accordingly, the proposed model draws a parallel between the typology of technological learning (learning by doing, by searching and by interacting) and the combination of action and reflection. It contends that learning by doing reflects the practical aspects of learning, or what Kolb defines as 'action', and learning by searching reflects the theoretical aspects, or what Kolb defines as 'reflection'. Accordingly, combining learning by doing and learning by searching can be modelled as a Kolb-like cycle combining action with reflection. This intra-level or horizontal combination is enabled by interaction or what the technological learning typology identifies as 'learning by interacting'. Interactions can also occur between learning levels (individual, group, organisation or inter-organisation), and this is considered in the following subsection.

\section{5-b- Inter-level learning (vertical differentiation)}

Learning is a systemic phenomenon where processes that occur at separate levels of aggregation interrelate with each other (Rousseau, 1985; Coghlan, 1997; Beeby and Booth, 2000). Learning is effective when knowledge is diffused and used to improve or change learner's capabilities. Tompkins (1995) argues that the diffusion results primarily from the "diffusion of knowledge and/or skill from the individual to members of the collective, and expansion of the collective's capacity to take effective action" (p.69). The diffusion occurs also when processes at all levels evolve to create mutually supportive relationships (Tompkins, 1995). This is often reflected in the local value created (e.g. supply chains involving multiple levels of collective action via - groups, organisations and interorganisations) (Porter and Kramer, 2011; OECD, 2014, p.20). Successful diffusion of knowledge is enabled therefore by a systemic learning phenomenon where the interplay involves all levels of aggregation from individual to inter-organisation. Coghlan (1997) and Beeby \& Booth (2000) illustrate the systemic nature of diffusion through a network-like model (Figure 3).

Figure 3: Network interaction between all learning levels

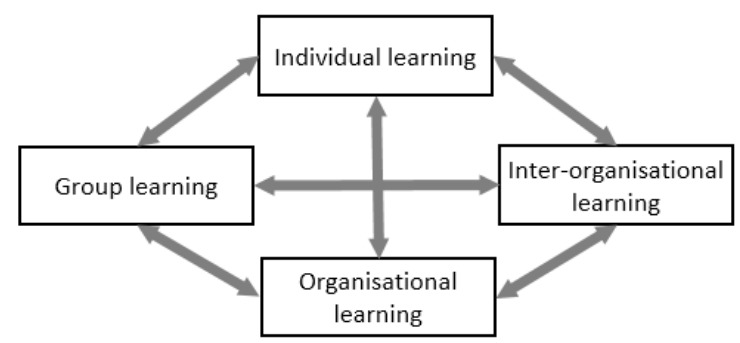

Source: adapted from Coghlan (1997) and Beeby \& Booth (2000) 
In the proposed model, diffusion is vertical when it refers to cross-level learning or relationships and horizontal when it refers to learning cycles occurring at each level of aggregation. The focus is on highlighting the elements that underlie the interplay between levels of aggregation (or cross-level learning) as well as the complexity of such relationships. As discussed in subsection 5-a, each learning level can be modelled horizontally according to a Kolb-like learning cycle. The proposed approach is then to draw connections vertically between Kolb's learning cycles at each level of aggregation. These connections are made by borrowing March (1991)'s concepts of 'exploration' and 'exploitation' and by juxtaposing them with Kolb's learning cycles. Prior to drawing these connections, it is useful to recall that March's concepts of 'exploration' and 'exploitation' are central to the study of adaptive processes. March stresses that the survival of any adaptive system requires an appropriate trade-off between exploration and exploitation. He warns that "systems that engage in exploration to the exclusion of exploitation are likely to find that they suffer the costs of experimentation [i.e. trialling] without gaining many of its benefits ......[and] conversely, systems that engage in exploitation to the exclusion of exploration are likely to find themselves trapped in suboptimal stable equilibria"(p.71).

Building on these concepts of exploration and exploitation, Holmqvist (2003) examines the interplay between organisational and inter-organisational learning. He highlights the duality in organisational learning, arguing that organisations engage in a process of exploration when they need to create variety in their experiences through experimentation (i.e. trialling) and taking risks, whereas, they engage in a process of exploitation when they need to create reliability in experience by focusing on and refining certain activities. A number of scholars underscore the cyclical relationship between exploration and exploitation and describe how exploration leads to exploitation and vice-versa (Dijksterhuis et al, 1999; Marengo, 1993; Olsen and Peters, 1996). Holmqvist (2003) argues that the cyclical exploration-exploitation dynamic occurs at the organisational level as well as beyond it, at inter-organisational level, where it orchestrates the interplay between these two levels. He thus proposes a dynamic model of intra- and inter-organisational learning. Thus, the present model draws connections between the two learning cycles: the exploration-exploitation cycle and Kolb's cycle at four levels of aggregation (i.e. individual, group, organisation, and inter-organisation). It proposes a theoretical dynamic model that explains the interplay between levels of aggregation.

Exploration in this model, refers to the process of a preliminary examination of a subject either in terms of experimentation (i.e. action or learning by doing) or conceptualisation (i.e. reflection or learning by searching). Exploitation, by contrast, refers to the process of making use of knowledge through 'mature' conceptualisation (i.e. reflection or learning by searching) or through active experimentation (i.e. action or learning by doing). These differentiations are paralleled to the phases comprising the knowledge maturing process, in terms of conceptualisation or idea generation (Maier and Schmidt, 2015) and the product developing process, in terms of experimentation and product development (Kahn, 2013). The preliminary examination of a concept refers to the first phases of conceptualisation or idea generation whereas the 'mature' conceptualisation refers to the advanced phases of conceptualisation and idea adoption. Similarly, the preliminary examination of experimentation refers to the first phases of product development, and active experimentation refers to the advanced phases of development.

Therefore, the learning cycle at each level of aggregation can be viewed as a continuous explorationexploitation cycle, and when juxtaposed with Kolb's cycle, it provides a four-step cycle (Figure 4): explorative action, explorative reflection, exploitative reflection, and then exploitative action. 
Figure 4: Exploration-exploitation cycle juxtaposed with Kolb's cycle

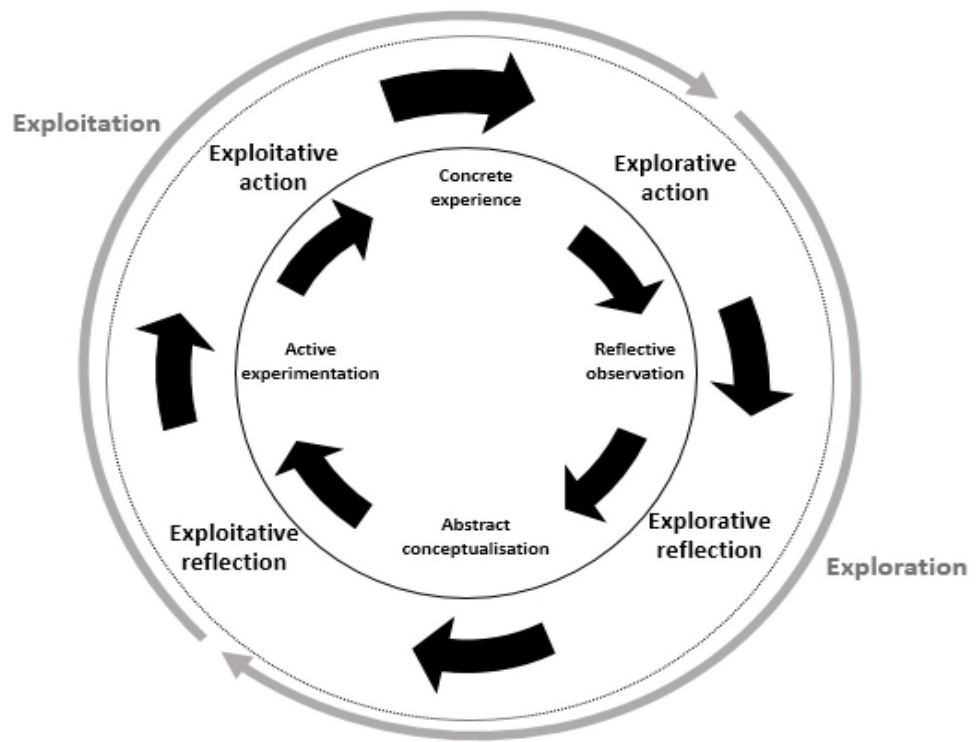

Source: Authors

Explorative action is where learners (e.g. individuals, groups, organisations and inter-organisations) are assigned a task (or experience). At this stage the process is still explorative. Learners have not yet internalised the principles behind concrete experience, and need to engage in explorative reflection, where they step back from the task and reflect on what has been done and explore the experience. Exploration at this stage is carried out through formulating questions and attempting to answer them.

Once reflection matures, learners conceptualise theories and models of what was experienced with the intention of exploiting them or putting them into practice. This stage is called exploitative reflection. Finally, learners attempt to plan how to test their models and theories, and how to enter into a new experience. In general, learners usefully exploit the experience by placing it into a context that is relevant to them. This stage is called exploitative action.

It is clear that any proposed model explaining the interplay between levels of aggregation should illustrate the systemic nature of the learning process (Coghlan, 1997; Beeby and Booth, 2000). This systemic nature is primarily underpinned by the relationships between each pair of learning levels of aggregation. For Isaacs (1993), dialogue is the essence of collective thinking and learning. He defines dialogue as "a sustained collective inquiry into the processes, assumptions, and certainties that compose everyday experience" (p.25). Based on this definition, the present model posits that learners, whether they are individuals, groups, organisations or inter-organisations, take part in intra-level and cross-level dialogues during the learning process. Intra-level dialogue occurs at the same level of aggregation and is represented through learning cycles (Figure 4). Cross-level dialogue is triggered between levels of aggregation and is represented in Figure 5. The complexity of crosslevel relationships is illustrated by the multitude of dialogue types or connections that any pair of learning levels can establish. Each pair and level reciprocally affects the other (or internalises from 
the other). Both levels are tied together through the following simplified combinations: exploitativeexploitative; exploitative-explorative; explorative-explorative; and explorative-exploitative (Figure 5a); or the full-length combinations: exploitative action-exploitative action; exploitative actionexploitative reflection; ...; explorative action-explorative action (Figure 5-b). Table 1 lists all dialogue combinations identified by the proposed model, together with their meanings in the context of technological learning.

Figure 5: Interplay between each pair of learning levels

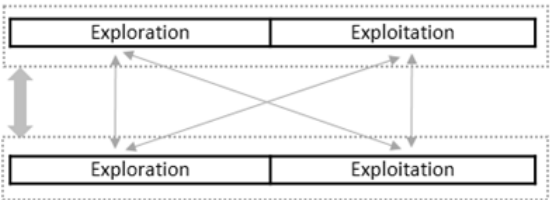

(a)

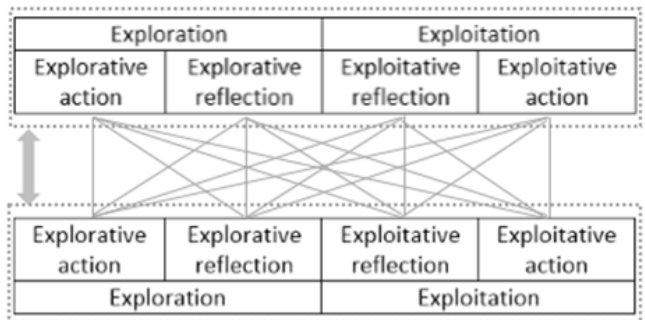

(b)

Source: Authors

Table 1 : Inter-level dialogue combinations

\begin{tabular}{|c|c|c|}
\hline General combinations & Detailed combinations & Meaning in the context of technological learning \\
\hline \multirow{4}{*}{ Exploitative-Exploitative } & Exploitative action-Exploitative action & \multirow{4}{*}{$\begin{array}{l}\text { Dialogue between } \\
\text { learner who (regularly) performs practical tasks } \\
\text { (e.g. manufacturing tasks) or matures conceptually } \\
\text { the tasks (e.g. mature design) } \\
\text { and } \\
\text { learner who (regularly) performs practical tasks } \\
\text { (e.g. manufacturing tasks) or matures conceptually } \\
\text { the tasks (e.g. mature design) }\end{array}$} \\
\hline & Exploitative action-Exploitative reflection & \\
\hline & Exploitative reflection-Exploitative action & \\
\hline & Exploitative reflection-Exploitative reflection & \\
\hline \multirow{4}{*}{ Exploitative-Explorative } & Exploitative action-Explorative action & \multirow{4}{*}{$\begin{array}{l}\text { Dialogue between } \\
\text { learner who (regularly) performs practical tasks } \\
\text { (e.g. manufacturing tasks) or matures conceptually } \\
\text { the tasks (e.g. mature design) } \\
\text { and } \\
\text { learner who tests and explores practical tasks (e.g. } \\
\text { laboratory experience) or conceptual ideas (e.g. } \\
\text { research) }\end{array}$} \\
\hline & Exploitative action-Explorative reflection & \\
\hline & Exploitative reflection -Explorative action & \\
\hline & Exploitative reflection-Explorative reflection & \\
\hline \multirow{4}{*}{ Explorative-Explorative } & Explorative action-Explorative action & \multirow{4}{*}{$\begin{array}{l}\text { Dialogue between } \\
\begin{array}{l}\text { learner who tests and explores practical tasks (e.g. } \\
\text { laboratory experience) or conceptual ideas (e.g. } \\
\text { research) } \\
\text { and } \\
\text { learner who tests and explores practical tasks (e.g. } \\
\text { laboratory experience) or conceptual ideas (e.g. } \\
\text { research) }\end{array}\end{array}$} \\
\hline & Explorative action-Explorative reflection & \\
\hline & Explorative reflection -Explorative action & \\
\hline & Explorative reflection-Explorative reflection & \\
\hline \multirow{4}{*}{ Explorative-Exploitative } & Explorative action-Exploitative action & \multirow{4}{*}{$\begin{array}{l}\text { Dialogue between } \\
\text { learner who tests and explores practical tasks (e.g. } \\
\text { laboratory experience) or conceptual ideas (e.g. } \\
\text { research) } \\
\text { and } \\
\text { learner who (regularly) performs practical tasks } \\
\text { (e.g. manufacturing tasks) or matures conceptually } \\
\text { the tasks (e.g. mature design) }\end{array}$} \\
\hline & Explorative action-Exploitative reflection & \\
\hline & Explorative reflection-Exploitative action & \\
\hline & Explorative reflection-Exploitative reflection & \\
\hline
\end{tabular}

Source: Authors 
The reciprocal effect between levels of learning also depends on the ability to interact. This ability can be explained by borrowing Hamel's (1991) concepts of 'transparency' and 'receptivity'. 'Transparency' refers to the openness of a learning level (individual, group, organisation, or interorganisation) to other levels by sharing experiences with them, and 'receptivity' refers to the ability to absorb knowledge that comes from other levels by internalising their experiences. Holmqvist (2003) employs these concepts to explain the relationship between organisational and interorganisational levels. The proposed model advocates generalising the use of these concepts to explain relationships between all levels of aggregation (individual, group, organisation and interorganisation). The reciprocal effect between levels of learning reflects the systemic nature of learning and shows that the phenomenon transcends learner boundaries, whether learners are individuals, groups, organisations or inter-organisations. However, illustrating learning's systemic nature in the form of networks (Figure 3 ) with a broad variety of possible combinations between levels of learning (Figure 5) does not necessarily imply intense cross-level interactions. Indeed, network-like representation seems to neglect the significance of 'vertical' barriers. These come about as a result of hierarchical relations (Argyris and Schön, 1996, p.26) between organisational levels plus "the complexity with which a given system level is organized, the size in physical space of its constituent units, the physical proximity of these units, their characteristics, and the distinctive structures and processes characterizing these units" (Rousseau, 1985, p.3). Figure 6 illustrates the interplay between learning levels and depicts the hierarchical aspect. The shaded area in this figure reveals that hierarchy is dominant in the intra-organisation context.

\section{Figure 6: Interplay between hierarchical learning levels}

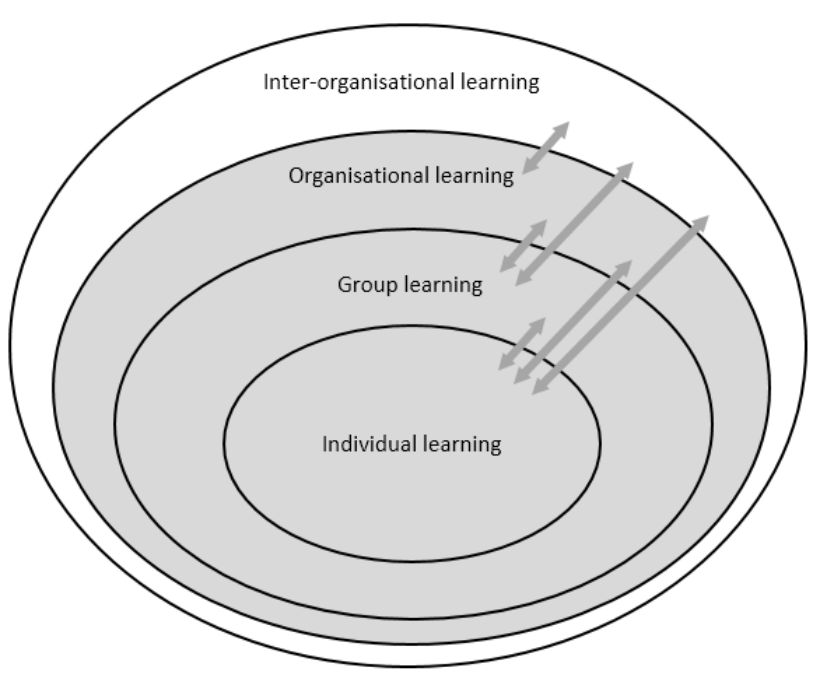

Source: Authors

A further argument in favour of choosing a hierarchical model to capture the systemic nature of learning is the presence of differing forms of authority (formal and informal) at the intraorganisational level (individual, group and organisation). Such forms of authority can hinder crosslevel or 'vertical' learning. Paradoxically, according to experiential learning theory, in order to make learning intentional, there is a need to create coordinating authorities at each level of learning. These authorities drive and orchestrate the 'horizontal' learning cycles and balance between action and reflection (Kolb, 1984) or between exploration and exploitation (Holmqvist, 2003). The lack of such authorities at inter-organisational level is a major barrier to learning (Baum and Ingram, 2002; 
Larsson et al, 1998). Indeed, a great deal of the systemic learning lies in the paradoxical effect of these authorities (hindering vs driving). Through these authorities, conditions and behaviours are aligned within and across different levels of aggregation (Hargadon, 2013, p.166), and learning curves can be shortened (p.170). The proposed model, employing horizontal and vertical differentiations, along with considerations related to hierarchy, is represented in Figure 7.

Figure 7: Experiential learning model

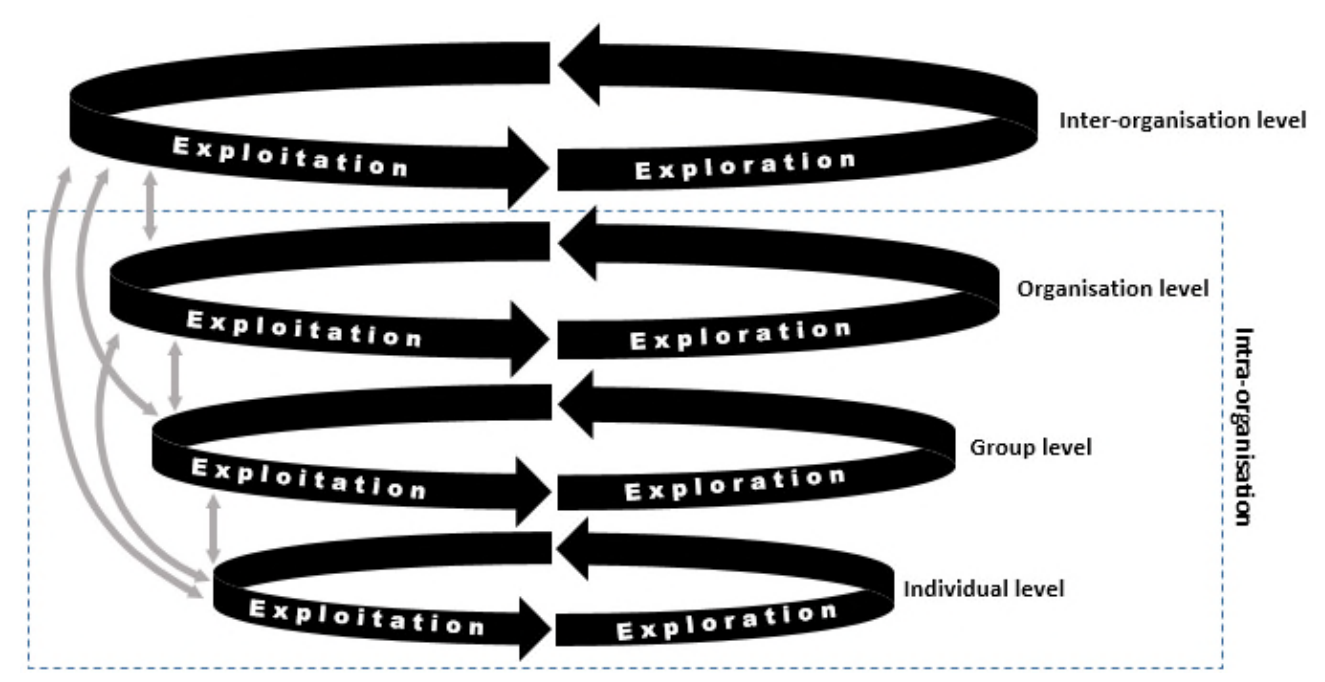

Source: Authors

\section{6- Applying the model to small satellite capability-building in Algeria}

The 'systemic experiential learning model' has been tested as part of a broader empirical study aimed at evaluating small satellite capability-building in Algeria. Algeria's strategy takes a twopronged approach: firstly, acquiring small satellite technology from abroad, and, secondly, diffusing the technology locally. Three small satellite collaborative projects with foreign companies (Alsat-1, Alsat-2, and Alsat-1B) have been implemented by one of the Algerian space agency's affiliates, namely the Centre of Satellite Development (or Centre de développement des Satellites-CDS), in order to acquire technology from abroad. Alsat-1 and Alsat-1B are two small satellites built jointly with SSTL-UK in 2000 and 2014. Alsat-2 comprises a pair of identical satellites (Alsat-2A and B) built jointly with Airbus-France in 2005 and 2012. CDS undertook steps to diffuse locally the technology acquired from abroad. The implementation of the systemic experiential learning model aims to evaluate the level of local diffusion of acquired knowledge. In other words, it evaluates learning occurring after the small satellite projects, within CDS and its environment, corresponding to the four learning levels: individual, group, organisation and inter-organisation. Engineers and scientists directly involved in the development of Alsat-1, Alsat-2, and Alsat-1B, are essentially those who possess the acquired knowledge. This knowledge stems from 'learning by doing' and 'learning by searching', and is supposedly enriched and converted through interactions (learning by interacting) into group opportunities before being embedded and amplified in the context of the organisation and inter-organisation.

\section{6-a- Data collection}


Based on a mixed method design, a quadrilateral data acquisition method has been used, incorporating four mutually reinforcing methods: secondary data; structured/semi-structured interviews; semi-structured/in-depth interviews; and participant observation. 48 interviews were conducted through three fieldwork campaigns, spread over a 13-month period (from April 2016 to May 2017). Data was gathered at three levels of analysis: individual and team level (micro level); organisational and inter-organisational level (meso level) and sectoral, national and international level (macro level). At the micro and meso levels, 40 mixed - structured and semi-structured interviews were conducted with members of former satellite project teams as well as with representatives from entities involved in satellite capability-building in Algeria and foreign satellite suppliers. Eight semi-structured and in-depth interviews were held at both the meso and macro levels. Interviews were held with representatives from the CDS and the Algerian Space Agency's local partners and top management. The participation rate for this study was $73.84 \%$. The questions were sent to interviewees well before the interviews to promote validity and reliability. They were selfadministered in the initial stage, and then interviewer-administered. To preserve interviewee anonymity, participants were assured that only aggregate data would be presented.

Participant observation was also conducted to collect data by the first author of the present paper, who has spent the past 16 years working in the space sector in Algeria. The observer has been in an interrupted involvement (i.e. previous or sporadic presence over time and revealed identity) (Easterby-Smith et al., 2012, p.144).

\section{6-b- Discussion of intra-level learning (horizontal differentiation)}

\section{Individual learning}

At the individual level, learning is effective when it combines action with reflection. Individuals involved in small satellite collaborative projects largely agreed (78\%) that a 'fair' combination of hands-on and theoretical knowledge was provided for each individual during the lifetime of the projects (Alsat-1, Alsat-2, and Alsat-1B). However, they are almost unanimously (98\%) disappointed with the imbalance in their assigned work activities after the conclusion of the projects. Most of them (92\%) consider their post-project activities were oriented too much towards theoretical research instead of practical implementation (i.e. engineering aspects). In general, they did not utilise the practical knowledge (i.e. development and engineering aspects) acquired during Alsat-1, Alsat-2 and Alsat-1B after these projects, and expressed concern that it was gradually eroding.

The effectiveness of the reflective component of learning (i.e. learning by searching), enabled by formal research and development, is also questionable in the case under study, because numerous research projects are not 'directly' linked to small satellite technology. Moreover, those related to small satellite technology do not go beyond the laboratory stage of development in terms of experimentation and simulation. This limitation is reflected in the absence of a patenting culture in CDS, evidenced by zero patent registrations at the time the survey was conducted. Interview responses on the reasons behind, firstly, the imbalance between research and engineering activities, and, secondly, the trend towards too much non-channelled research. These constraints have resulted in poor alignment of individual effort with the objectives of small satellite development. It is clear, then, that learning at the individual level is ineffective, because its purpose is not always aligned with organisational goals, carrying the downside that the learning cycle has not effectively combined action (i.e. learning by doing) and reflection (i.e. learning by searching).

\section{Group learning}


The rationale of the evaluation is to trace knowledge flow from its acquisition abroad to its diffusion locally, and thus evaluation of group learning begins by evaluating the activities of the satellite project teams subsequent to project completion. The idea is to determine whether subsequent group knowledge is built on previous experience. Alsat-1, Alsat-2, and Alsat-1B teams were virtually dismantled following completion of the projects, with members scattered across various organisational structures. In addition, $10 \%$ of team members gradually left the organisation after project completions (mainly as a consequence of 'brain drain' to Western organisations). Team members raised concerns as to the difficulties of interaction, because of organisational boundaries and lack of visibility as to their missions. Interruptions of group work, member turnover and confinement into separate departments led inevitably to degradation of previously acquired group knowledge. The three group memories built up during the three satellite projects remained isolated from one another (i.e. no project member had access to any other project's database). Isolation was justified, inter alia, by considerations relating to protection of the technology provider's intellectual property rights and internal ASAL non-disclosure agreements signed by project members.

The fieldwork further revealed that discontinuities exist, in varying degrees, in the progression of teamwork based on consecutive teams' experiences formed out of the Alsat-1, Alsat-2 and Alsat-1B projects. This raises the question as to whether interrupted teamwork has been offset by countervailing forms of collective work (or group formation). Satellite development activities are formally located within CDS, and categorised according to two types of groups: firstly, nine (09) thematic groups containing individuals clustered according to technological themes, and, secondly, four (04) 'functional' groups organised according to functional structures. These groups can be represented by reference to a matrix structure (Figure 8 ). Vertical solid lines representing the linear chain of command and horizontal dotted lines representing cross-functional relations among the various thematic groups. Black circles denote the number of personnel in each thematic group, including the functional authority. 
Figure 8: CDS group matrix (functional vs thematic groups)

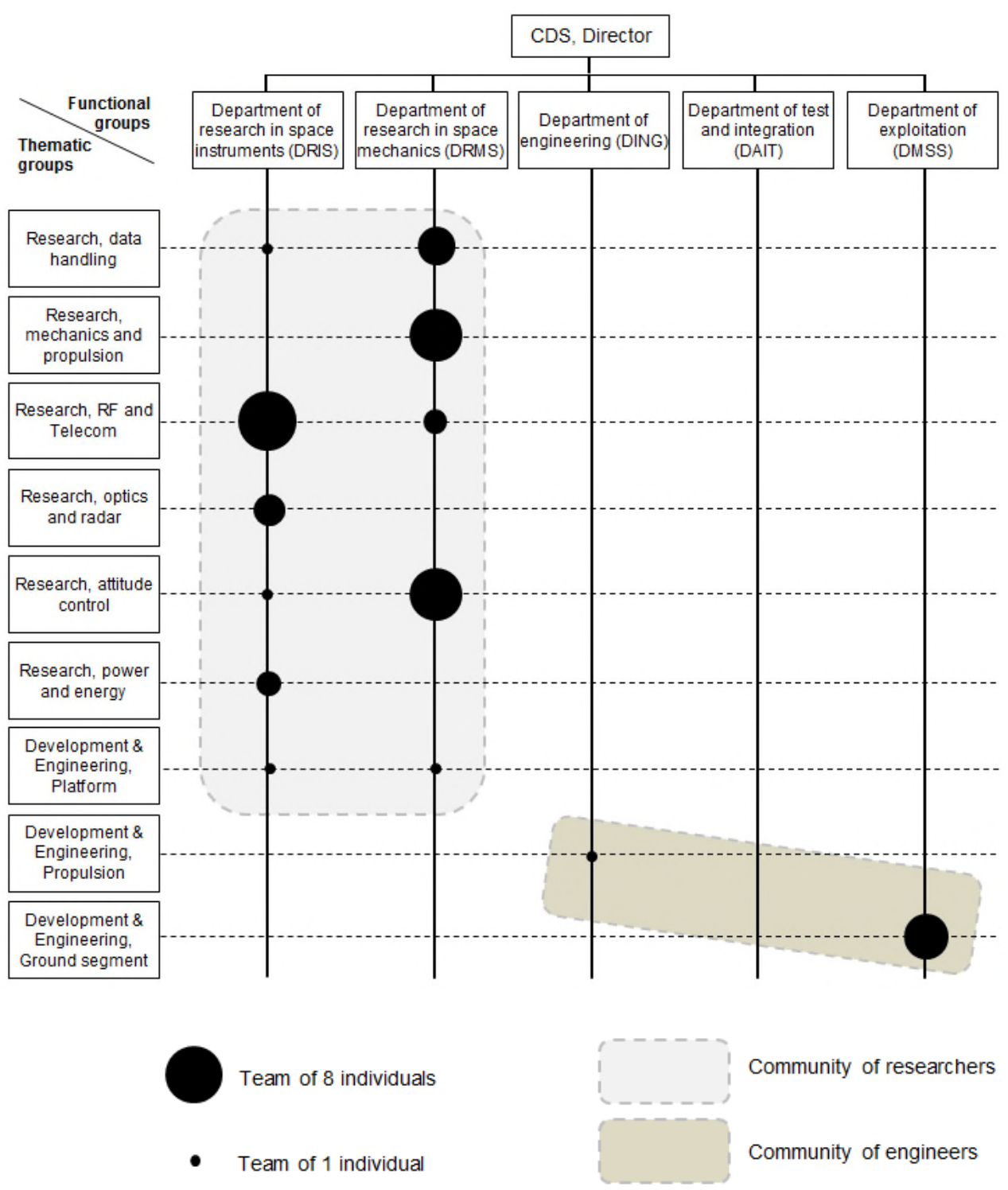

Source: Authors

Six out of nine thematic groups are dedicated to research (i.e. learning by searching), with each research department hosts three groups (Figure 8). According to interviewees, very few crossfunctional activities are conducted in terms of research. In addition, group activities are heavily slanted towards research that does not go beyond the laboratory stage (i.e. experimentation and 
simulation). Also, whilst Group research foci are not clearly aligned with the objective of developing small satellites, the groups do interact (i.e. learning by interacting) with some university-based research teams (e.g. the universities of Oran-USTO, Sidi Belabes and Tlemcen). The scarcity of Development and Engineering group activities is noticeable (Figure 8). The only engineering activity (i.e. learning by doing) worth mentioning is conducted by the Development and Engineering Ground Segment group. This particular group has been able to align its activity with the objective of developing small satellites, and combine development and engineering skills in order to deliver some in-house technical solutions related to the ground segment.

In summary, then, interactions between individuals resulted in the creation of nine groups. Group components are virtually mono-departmental (almost every group's members are from the same department). This likely reflects separate individual efforts (i.e. individual learning) being converted to group level efforts (i.e. group learning) within the same functional department. No significant cross-functional group is identified, particularly between departments in charge of research and those in charge of development and engineering, resulting in the groups not having members with diverse learning styles (Kayes et al., 2005). Consequently, learning at research group level is not clearly aligned with the objective of developing small satellites. Moreover, learning is not effective because groups do not combine reflection (i.e. learning by searching) with action (i.e. learning by doing). Learning at Development and Engineering group level is aligned with the objective of developing small satellites. Interaction (i.e. learning by interaction) has facilitated alignment. However, learning is not effective because the group does not combine reflection (i.e. learning by searching) with action (i.e. learning by doing).

\section{Organisational and inter-organisational learning}

Organisational learning is a system-level learning where all organisation members, be they individuals or groups, collectively use their capabilities in order to achieve organisational goals. The aim of this subsection is to evaluate whether learning within CDS occurs at the organisational level. Emphasis is on whether inter-group activities are intense enough to be considered as organisational. As mentioned in the previous subsection, no common objectives exist between the Alsat-1, Alsat-2 and Alsat-1B project teams. The teams are virtually isolated from each other for reasons that relate, inter alia, to protection of the technology provider's intellectual property rights and internal nondisclosure agreements. Instead, CDS management has put in place a new organisational architecture based on nine (09) thematic groups and four (04) functional groups. Figure 8 shows that crossfunctional activities are virtually non-existent. This is reflective of a significant dearth in interactions between functional groups (i.e. across organisational boundaries). With respect to thematic group interactions (i.e. vertical interactions in Figure 8), the only interactions revealed are those occurring within the Department of Research in Space Mechanics, where groups undertake certain collaborative activities. These findings reveal once again the striking imbalance between research activities (i.e. learning by searching) and engineering activities (i.e. learning by doing) within CDS at inter-group (or organisational) level.

The findings additionally reveal the ineffectiveness of the cross-functional and cross-thematic structure put in place at CDS (Figure 8). Such a matrix structure should fundamentally be built around the immediacy and intensity of interactions between groups (i.e. learning by interacting). However, such interactions are missing. From a Kolb-cycle perspective (subsection 3-c), CDS does not diversify its experience, as its limited inter-group activity is oriented towards research. Also, the lack of interaction jeopardises CDS's ability to collectively integrate and interpret knowledge acquired from previous experience. Limited and isolated CDS engineering capabilities prevent the 
translation of knowledge into tangible outcomes. Consequently, CDS is not a learning organisation with regard to developing small satellites. Moreover, from the perspective of inter-organisational learning, CDS has been designated as the lead institution in Algeria charged with developing small satellite capabilities. A network of organisations is supposed to be built around CDS and contribute to the goal of satellite development. However, CDS as a unified and cohesive whole does not exist from a learning perspective, and is thus incapable of addressing learning cycles at the interorganisational level.

\section{6-c- Discussion of inter-level learning (Vertical differentiation)}

In the case of CDS, there is evidence to suggest that two types of activity trigger two distinct learning dynamics. The first is satellite collaborative projects with foreign companies, where project teams triggered interactions with one local partner regarding engineering issues (i.e. manufacturing mechanical components). These interactions were 'exploitative-exploitative' when framed according to the proposed 'systemic experiential learning model' (Table 2). These one-time actions ceased after project completion.

Table 2: Dialogue between project groups and the local partner

\begin{tabular}{|l|l|l|}
\hline General combinations & Detailed combinations & \multicolumn{1}{c|}{ Dialogue between } \\
\hline & Exploitative action-Exploitative action & Nil \\
\cline { 2 - 3 } & Exploitative action-Exploitative reflection & $\begin{array}{l}\text { Alsat-2 and Alsat-1B groups, who mature the } \\
\text { task conceptually (using mature design of the } \\
\text { mechanical components) } \\
\text { and }\end{array}$ \\
\cline { 2 - 4 } & Exploitative reflection-Exploitative action & $\begin{array}{c}\text { Local partner ECA*, who (regularly) performs } \\
\text { practical tasks (regularly manufacturing } \\
\text { mechanical components) }\end{array}$ \\
\cline { 2 - 3 } & Exploitative reflection-Exploitative reflection & \multicolumn{1}{c|}{ Nil } \\
\hline
\end{tabular}

${ }^{*} E C A:$ Aeronautical Construction Enterprise. CDS's local partner.

Source: Authors

The second activity was undertaken by CDS outside the collaborative projects. As illustrated in Figure 8 , two communities of learners are formed. The community of engineers and the community of researchers (be they individuals or groups). Intra-engineering interactions are fledgling. These interactions are exploitative-exploitative, as per the proposed 'systemic experiential learning model' (Table 3). However, this research community has virtually no interaction with its environment (inside and outside CDS).

Table 3: Dialogue within engineering groups 


\begin{tabular}{|l|l|l|}
\hline General combinations & \multicolumn{1}{|c|}{ Detailed combinations } & \multicolumn{1}{c|}{ Dialogue between } \\
\hline \multirow{5}{*}{ Exploitative-Exploitative } & Exploitative action-Exploitative action & $\begin{array}{l}\text { Individuals within the group (development \& } \\
\text { engineering ground segment) on } \\
\text { manufacturing (or practical implementation) } \\
\text { aspects }\end{array}$ \\
\cline { 2 - 3 } & Exploitative action-Exploitative reflection & $\begin{array}{l}\text { Individuals within the group (development \& } \\
\text { engineering ground segment) on } \\
\text { manufacturing (or practical implementation) } \\
\text { aspects and mature concepts (e.g. mature } \\
\text { design) }\end{array}$ \\
\cline { 2 - 4 } & Exploitative reflection-Exploitative action & $\begin{array}{l}\text { Individuals within the group (development \& } \\
\text { engineering ground segment) on mature } \\
\text { concepts (e.g. mature design) and } \\
\text { manufacturing (or practical implementation) } \\
\text { aspects }\end{array}$ \\
\cline { 2 - 4 } & Exploitative reflection-Exploitative reflection & $\begin{array}{l}\text { Individuals within the group (development \& } \\
\text { engineering ground segment) on mature } \\
\text { concepts (e.g. mature design) }\end{array}$ \\
\cline { 2 - 3 }
\end{tabular}

Source: Authors

From the standpoint of the community of researchers, intra-community interactions are emerging. Many research groups are active, but inter-group activities are still poorly developed. The community of researchers also continuously interacts with its external environment by conducting research with other communities of researchers (e.g. universities). Both intra- and inter-community interactions are not necessarily channelled towards small satellite development. These interactions are predominantly 'explorative-explorative' again as per the proposed 'systemic experiential learning model' (Tables 4 and 5).

Table 4: Dialogue within research groups

\begin{tabular}{|l|l|l|}
\hline General combinations & \multicolumn{1}{|c|}{ Detailed combinations } \\
\hline \multirow{5}{*}{ Explorative-Explorative } & Explorative action-Explorative action & $\begin{array}{l}\text { Individuals within research groups (e.g. data } \\
\text { handling, mechanics and propulsion, RF and } \\
\text { Telecom) on laboratory experiences and } \\
\text { simulations }\end{array}$ \\
\cline { 2 - 3 } & Explorative action-Explorative reflection & $\begin{array}{l}\text { Individuals within research groups (e.g. data } \\
\text { handling, mechanics and propulsion, RF and } \\
\text { Telecom) on laboratory experiences, simulations } \\
\text { and theoretical research }\end{array}$ \\
\cline { 2 - 4 } & Explorative reflection -Explorative action & $\begin{array}{l}\text { Individuals within research groups (e.g. data } \\
\text { handling, mechanics and propulsion, RF and } \\
\text { Telecom) on theoretical research and laboratory } \\
\text { experiences and simulations }\end{array}$ \\
\cline { 2 - 4 } & Explorative reflection-Explorative reflection & $\begin{array}{l}\text { Individuals within research groups (e.g. data } \\
\text { handling, mechanics and propulsion, RF and } \\
\text { Telecom) on theoretical research }\end{array}$ \\
\cline { 2 - 3 } & &
\end{tabular}

Source: Authors

Table 5: Dialogue of research groups with external communities of researchers 


\begin{tabular}{|c|l|l|}
\hline General combinations & \multicolumn{1}{|c|}{ Detailed combinations } & \multicolumn{1}{c|}{ Dialogue between } \\
\hline \multirow{5}{*}{ Explorative-Explorative } & Explorative action-Explorative action & $\begin{array}{l}\text { Research groups (e.g. data handling, mechanics } \\
\text { and propulsion, RF and Telecom) and groups in } \\
\text { universities (e.g. Oran, Sidi Belabes, Tlemcen) on } \\
\text { laboratory experiences and simulations }\end{array}$ \\
\cline { 2 - 3 } & Explorative action-Explorative reflection & $\begin{array}{l}\text { Research groups (e.g. data handling, mechanics } \\
\text { and propulsion, RF and Telecom) and groups in } \\
\text { universities (e.g. Oran, Sidi Belabes, Tlemcen) on } \\
\text { laboratory experiences, simulations and } \\
\text { theoretical research }\end{array}$ \\
\cline { 2 - 4 } & Explorative reflection -Explorative action & $\begin{array}{l}\text { Research groups (e.g. data handling, mechanics } \\
\text { and propulsion, RF and Telecom) and groups in } \\
\text { universities (e.g. Oran, Sidi Belabes, Tlemcen) on } \\
\text { laboratory experiences, simulations and } \\
\text { theoretical research }\end{array}$ \\
\cline { 2 - 4 } & Explorative reflection-Explorative reflection & $\begin{array}{l}\text { Research groups (e.g. data handling, mechanics } \\
\text { and propulsion, RF and Telecom) and groups in } \\
\text { universities (e.g. Oran, Sidi Belabes, Tlemcen) on } \\
\text { theoretical research }\end{array}$ \\
\hline
\end{tabular}

Source: Authors

\section{7- Conclusion}

Algeria has engaged in building small satellite technological capability through the acquisition of satellite technology from abroad, and the diffusion of that technology locally. This study has attempted to evaluate the local diffusion of small satellite technology. A 'systemic experiential learning model' is proposed for evaluating the level of knowledge diffusion or learning occurring within the Centre of Satellite Development (CDS) and its environment, corresponding to the four learning levels, namely, individual, group, organisation and inter-organisation. This model involves learning processes that occur "separately" at all levels of aggregation (individual, group, organisation and inter-organisations), along with the cross-level processes that reflect reciprocal affects between these levels. The proposed framework is built over three stages: first, drawing parallels between the typology of technological learning -learning by doing, by searching and by interacting- and Kolb's cyclical combination of action and reflection. Second, the generalisation of Kolb-like experiential learning cycles over all learning levels, and third, the connection of learning levels by borrowing March's concepts of "exploration" and "exploitation".

The model has been applied to CDS as the lead institution in the Algerian Space Agency charged with developing small satellite capabilities. The implementation of the model revealed that learning at individual, group and organisational levels (intra-level) is ineffective. Learning cycles are not completed and a striking imbalance exists between research activities (i.e. reflection or learning by searching) and engineering activities (i.e. action or learning by doing). Indeed, building technological capability involves building complementary and balanced capabilities in terms of engineering, development and research. Data collected revealed that CDS has taken a poorly balanced set of actions focused on research investment (i.e. learning by searching) and the research that has been conducted does not go beyond the laboratory setting and is not always aligned with the goals of small satellite capability-building. At the same time, less attention has been paid to engineering and development (i.e. learning by doing). The implementation of the model also revealed that interactions between levels of aggregation (inter-level) are limited and not necessarily channelled towards small satellite development.

Ineffectiveness of learning within and between levels of aggregation (i.e. individual, group, organisation) prevented CDS from becoming a learning organisation with regard to developing small 
satellites. CDS does not exist as a unified and cohesive whole from a learning perspective. It is thus incapable of addressing learning cycles and interactions at the inter-organisational level. In other words, small satellite development is essentially confined within CDS and detached from its local environment. Consequently, establishing a local satellite supply chain is not tenable at this development stage. Building a local supply chain relies on CDS's interactions with other organisations involved in satellite development, but a superficial level of interaction has been evidenced.

In the development of small satellites in Algeria, this study reveals that learning cycles are incomplete and many links are missing for learning to be systemic. Considerable effort should be made to strike the right balance between action (i.e. learning by doing) and reflection (i.e. learning by searching) and linking learners at all levels of aggregation through diversified combinations.

Finally, it is important to recognise that the proposed 'systemic experiential learning model' has been tested under the particular setting of small satellite capability-building in the Algerian context. The model carries the potential to apply to other technological learning processes within different contexts, provided that is it empirically tested, enriched and adapted through further research.

\section{References}

Alvarez, S.A., Busenitz, L.W., 2001. The Entrepreneurship of Resource-Based Theory. Journal of Management 27, 755-775.

Argote, L., Epple, D., 1990. Learning Curves in Manufacturing. Science 247, 920-924.

Argyris, C., Schön, D. A., 1996. Organizational Learning II: Theory, Method, and Practice. Addison-Wesley Publishing Company.

Baum, J. A., Ingram, P. (2002). Interorganizational learning and network organization: Toward a behavioral theory of the interfirm, in: Augier, M., March, J. G., Cyert, R. M. (Eds), The economics of choice, change, and organization: Essays in memory of Richard M. Cyert, Edward Elgar Pub, pp.191-218.

Beard, C. M., Wilson, J. P., 2006. Experiential learning: A best practice handbook for educators and trainers (2nd edition). Kogan Page Publishers.

Bederina, M. L., 2011. Pour une lecture stratégique du système éducatif algérien, Communication in Centre de recherche stratégique et sécuritaire, Algiers (Accessed on 12 September 2016 at www.elmoudjahid.com/fr/mobile/detail-article/id/20328).

Beeby, M., Booth, C., 2000. Networks and inter-organizational learning: a critical review. The learning organization $7(2), 75-88$.

Bell, M., 1984. Learning and the accumulation of industrial technological capacity in developing countries. In: Fransman, M., King, K., (Eds.). Technological Capability in the Third World. Palgrave Macmillan, pp.187209.

Chitour, C., 2016. Interview on the educative system in Algeria. La foundation Agotavox (Accessed on 12 september 2016 at www.agoravox.fr/tribune-libre/article/quel-systeme-educatif-pour-quelle-183083).

Coghlan, D., 1997. Organizational learning as a dynamic interlevel process. Current topics in management 2, 27-44.

Dasgupta, M., 2012. Conceptual Paper: Organizational Learning and its Practices. Sage Open. 
Dijksterhuis, M. S., Van den Bosch, F. A., Volberda, H. W., 1999. Where do new organizational forms come from? Management logics as a source of coevolution. Organization Science 10(5), 569-82.

Dixon, N. \& Flood, C. (1993), Questioning the learning organization concept, in: Scott, S., Spencer, B., Thomas A. (Eds), Learning for Life: Readings in Canadian Adult Education, Toronto, Ontario, Canada: Thompson, pp. 140-152.

Dixon, N., 1999. The organizational learning cycle: How we can learn collectively. Gower Publishing, Ltd.

Dosi, G., 1982. Technological paradigms and technological trajectories: A suggested interpretation of the determinants and directions of technical change. Research Policy 11, 147-162.

Easterby-Smith, M., Thorpe, R., Jackson, P., 2012. Management research. Forth Edition, SAGE Publications Ltd.

Garud, R. 1997. On the distinction between know-how, know-what and know-why. Advances in strategic management 14, pp. 81-101.

Garud, R., Rappa, M.A., 1994. A Socio-Cognitive Model of Technology Evolution: The Case of Cochlear Implants. Organization Science 5(3), 344-62.

Gill, S.J., 2010. Developing a Learning Culture in Non-profit Organizations. Sage Publication, pp. 53-74.

Hamel, G., 1991. Competition for competence and interpartner learning within international strategic alliances. Strategic Management Journal 12(S1), 83-103.

Hargadon, A. (2013). Brokerage and Innovation, in: Dodgson, M., Gann, D. M., Phillips, N. (Eds), The Oxford Handbook of Innovation Management. Oxford University Press, Oxford, pp. 163-180

Holmqvist, M., 2003. A dynamic model of intra- and inter-organizational learning. Organization studies 24(1), 95-123.

Ingram, P., 2002. Interorganizational learning, in: Baum, J.A.C. (ed.). The Blackwell companion to organizations. Oxford: Blackwell Business, pp. 642-63.

Isaacs, W. N., 1993. Taking flight: Dialogue, collective thinking, and organizational learning. Organizational dynamics 22(2), 24-39.

Kahn, K.B., 2013. The PDMA Handbook of New Product Development. $3^{\text {rd }}$ edition. John Wiley \& Sons.

Kayes, A. B., Kayes,C., Kolb, D.A., 2005. Experiential learning in teams. Simulation \& Gaming 36(3), 330-54.

Kenney, M., 2001. The temporal dynamics of knowledge creation in the information society. Knowledge and emergence, 93-110.

Kim, L., 1997. Imitation to Innovation: The Dynamics of Korea's Technological Learning. Harvard Business School Press.

Kim, D.H., 1993. A framework and methodology for linking individual and organizational learning: Application in TQM and product development. PhD thesis, Sloan school of management, MIT.

Kolb, A.Y., Kolb, D.A., 2005. The Kolb Learning Style Inventory, Technical Specifications, Version 3.1. Experience Based Learning Systems, Inc., HayGroup.

Kolb, D. A., 1984. Experiential learning: Experience as the source of learning and development, Prentice-Hall, Inc., Englewood Cliffs. New Jersey.

Larsson, R., Bengtsson, L., Henriksson, K., Sparks, J. 1998. The Interorganizational Learning Dilemma: Collective knowledge Development is Strategic Alliances. Organization Science 9(3), 285-305.

Maier, R., Schmidt, A., 2015. Explaining organizational knowledge creation with a knowledge maturing model. Knowledge Management Research \& Practice 13, 361-81. 
Malerba, F., 1992. Learning by firms and incremental technical change. The Economic Journal 102, 845-859.

March, J. G., 1991. Exploration and exploitation in organizational learning. Organization science 2(1), 71-87.

Marengo, L., 1993. Knowledge distribution and coordination in organizations: On some social aspects of the exploitation vs. exploration trade-off. Revue Internationale de Systémique 7(5), 553-571.

Mills, T. M., 1967. The sociology of small groups. Englewood Cliffs, NJ: Prentice Hall.

OECD, 2014. The Space Economy at a Glance 2014. OECD Report (downloaded on 07 February 2015 from http://www.asaspazio.it/wp-content/uploads/2014/11/The-Space-Economy-at-a-Glance-2014.pdf

Olsen, J., Peters, G. (Eds), 1996. Lessons from experience: Experiential learning in administrative reforms in eight democracies. Oslo: Scandinavian University Press.

Piek, H., 1998. Technology Development in Rural Industries - A study of China's collectives. Intermediate Technology Publications Ltd.

Porter, M.E., Kramer, M.R., 2011. The big idea: Creating Shared Value: how to reinvent capitalism -- and unleash a wave of innovation and growth. Harvard Business Review (Jan-Feb), 1-17.

Rousseau, D. M., 1985. Issues of level in organizational research: Multi-level and cross-level perspectives. Research in organizational behavior 7(1), 1-37.

Russ-Eft, D., Preskill, H.S., Sleezer, C., 1997. Human Resource Development Review: Research and Implications. Sage.

Saad, M., 2004. Issues and challenges arising from the application of innovation strategies based on the triple helix culture: Experience of the incubation system in Algeria. International Journal of Technology Management and Sustainable Development 3(1), 17-34.

Saad, M., Zawdie, G., 2005. From technology transfer to the emergence of a triple helix culture: The experience of Algeria in innovation and technological capability development. Technology Analysis and Strategic Management 17(1), 89-103.

Stevens, M. A., Campion, M. J., 1994. The knowledge, skill and ability requirements for teamwork: Implications for human resource management. Journal of Management 20, 503-530.

Swieringa, J., Wierdsma, A., 1992. Becoming a Learning Organization: Beyond the Learning Curve. AddisonWesley.

Teece, D.J., 2000. Firm Capabilities and Economic Development: Implications for newly industrializing economies. In: Kim, L., Nelson, R.R., (Eds.). Technology, Learning, and Innovation: Experiences of Newly Industrializing Countries. Cambridge University Press.

Tennant, M., 2006. Psychology and adult learning (3rd edition). Routledge.

Tompkins, T. C., 1995. Role of diffusion in collective learning. The International Journal of Organizational Analysis 3(1), 69-85.

UNIDO Industrial Development Report, 2005. Capability building for catching-up: Historical, empirical and policy dimensions. United Nations Industrial Development Organization.

Varsakelis, N. C., 2006. Education, political institutions and innovative activity: A cross-country empirical investigation. Research Policy 35(7), 1083-90 


\section{Contributor(s) Details:}

Ahmed Ayad is a researcher at the Centre for Defence Management and Leadership, Cranfield University, The Defence Academy of the UK.

Contact: CDML, Cranfield University, DA, Shrivenham, SN6 8LA, UK.

E-mail: aayad@asal.dz; a.ayad@cranfield.ac.uk

https://orcid.org/0000-0003-1831-9573

Edith Wilkinson is a senior research fellow at the Centre for International Security and Resilience, Cranfield University, The Defence Academy of the UK. Contact: CDML, Cranfield University, DA, Shrivenham, SN6 8LA, UK.

E-mail: e.m.wilkinson@cranfield.ac.uk

https://orcid.org/0000-0003-1446-612X

Ron Matthews is a professor at the Centre for Defence Management and Leadership, Cranfield University, The Defence Academy of the UK.

Contact: CDML, Cranfield University, DA, Shrivenham, SN6 8LA, UK.

E-mail: r.g.matthews@cranfield.ac.uk

https://orcid.org/0000-0002-5823-5473

Ahmed Ayad, Edith Wilkinson and Ron Matthews have asserted their right under the Copyright, Designs and Patents Act, 1988, to be identified as the authors of this work in the format that was submitted to Intellect Ltd 